\title{
Realitas Kehidupan dalam Perspektif Antropologis
}

\author{
Mudjahirin Thohir \\ Fakultas Ilmu Budaya, Universitas Diponegoro \\ mudjahirinthohir@ymail.com
}

\begin{abstract}
to be able to live normally, human being struggle to fulfill their basic needs. The human basic needs are: biological, social, and integrative. Biological needs include: food, clothing, and shelter. Social needs include: interact, cooperate, compete, and social order. Integrative needs include the need for: freedom in justice in accordance with the agreed common reference. So that regularity of life is realized, then guidelines are needes that are concidered true and good. There are five types of guidelines as a reference, namely: constitutive faith, cognitive, evaluative, ethical, and expressive. This is a reference as the ideal culture of society. Although there are such guidelines, but in real practice (real clture) violations often occur, including because of individual or group interest. As in ilustraton, it can be seen in the world of football, the concept of fairplay is manifested in the form of inappropriate actions. Not to mention in the political and economic world. From this angle the concepts of fairness and justice are always warmly studied. This paper discusses about it from the social sciences perspective, especially anthropology.
\end{abstract}

Keywords: Basic need; guideline; ideal culture; real culture; fairplay.

\section{Intisari}

Untuk dapat hidup secara normal, manusia berjuang untuk memenuhi kebutuhan dasarnya. Kebutuhan-kebutuhan dasar itu ialah kebutuhan biologis, sosial, dan integratif. Kebutuhan biologis meliputi pangan, sandang, dan papan. Kebutuhan sosial meliputi kebutuhan berinteraksi, bekerjasama, dan bersaing. Kebutuhan integratif meliputi nilai-nilai, agar kegiatan bekerja sama maupun bersaing didasari oleh koridor nilai-nilai dan norma hukum yang adil. Untuk dapat memenuhi kebutuhan dasar tersebut, secara ideal (ideal culture) masyarakat manusia memerlukan pedoman yang dianggap benar dan baik. bermuara kepada lima acuan, yaitu: konstitutif, kognitif, evaluatif, etik, dan ekspresif. Meskipun sudah ada pedoman, tetapi dalam kebudayaan riil (real culture) yakni dalam tataran praktik kehidupan, pedoman-pedoman tadi sering dilanggarnya. Dari sinilah nilai dan norma-norma hukum, hampir selalu menjadi ajang perdebatan, sebagaimana ilustrasi konsep fair play dalam pertandingan sepakbola. Tulisan ini mendiskusikan mengenai persoalan adil dan keadilan sosial ditinjau dari perspektif antropologis.

Kata kunci: Kebutuhan dasar; acuan; budaya ideal; budaya riil; fairplay.

\section{Pendahuluan}

Pandangan, tindakan, atau niatan yang semula masalah kehidupan biasa, bahkan mulia, tetapi ketika ia diwujudkan dalam kehidupan sosial, berkemungkinan menjadi berurusan dengan hukum. Sebaliknya, niat jahat bahkan perbuatan jahat yang secara kasat mata 
melawan hukum, dalam fakta sosial bisa terbebas dari jeratan hukum. Dialektika kehidupan demikian ini, mengindikasikan bahwa hukum sebagai hasil konstruksi manusia yang digunakan untuk kepentingan masyarakat manusia: keteraturan sosial, kontrol sosial, demi terwujudkan kehidupan sosial yang nyaman, adil, dan beradab, menjadi patut dipertanyakan dan didiskusikan untuk bagaimana kembali pada fungsi utamanya: membangun atau setidaknya memberi sumbangan atas nama peradaban.

Tulisan ini akan mengkaji bagaimana realitas kehidupan masyarakat manusia yang multikultural, menjalankan tugas memenuhi kebutuhan dasariahnya sebagai manusia berdasarkan acuan-acuan tindakan yang normal dilihat dari perspektif antropologis. Pertanyaannya lalu, konsep adil dan keadilan itu substansial atau legal formal?

\section{Metode Penelitian}

Sikap atau perbuatan atau keputusan yang dinilai adil, tentu terjadi ketika (sang pengadil; peneliti sosial) tahu duduk persoalan atas peristiwa itu sendiri. Peristiwa itu dalam bahasa semiotik, bisa disebut sebagai "text". Teks merupakan kata lain dari sign (tanda). Baik menggunakan istilah text atau sign, oleh Peirce dilihat ke dalam tiga jenis: ikon, indeks, dan simbol. Makna dan pesan di balik text sebagai simbol, dalam kajian hermeneutiknya baru bisa dimengerti kalau dirunut secara berjenjang dan secara berulang (sebagaimana logika fenomenologi) melewati: pretext - text - beyond the text - off the text. Proses demikian penting karena asumsi bahwa "all the behaviors are meaningful". Lantas makna dan pesan seperti apa agar bisa dipahami dan diputuskan perkara kasus tadi secara adil? Pertama, kembalikan kepada cara pandang pelakunya (emic perspective), bukan etic perspective. Pilihan kepada emic perspective juga harus secara cermat apakah tindakan orang-orang dalam kasus tadi, bersifat kesungguhan atau kepura-puraan (lihat penjelasan Ervin Goffman): front stage atau back stage? Setelah itu, sikap kita sendiri (baik sebagai penegak hukum atau peneliti sosial) bersikap netral, cermat, dan berkesimpulan berdasarkan data (realitas). Ada tiga contoh kasus untuk menggambarkan persoalan kehidupan yang berujung kepada persoalan hukum. Pertama, dialognya dua orang cidal; kedua soal ajakan, dan ketiga masalah ajaran keagamaan. 


\section{Hasil dan Pembahasan}

\section{Kajian Tiga Kasus}

Pada kasus pertama, ada seseorang yang kebetulan lisannya cidal, masuk ke suatu toko bermaksud membeli beberapa barang. Tetapi ketika dia menyampaikan maksudnya (tentu bicaranya cidal), ternyata oleh sang pemilik toko dianggap sebagai penghinaan karena kebetulan sang pemilik toko juga cidal. Akhirnya terjadilah pertengkaran bahkan penganiayaan. Orang-orang cidal ini secara metaforik sering digambarkan dalam film-film india antara pencuri dan polisi.

Kasus kedua, soal tilpun. Suatu ketika ada ditilpun oleh seseorang yang dikenal sebagai mantan pacar isteri. Isinya meminta ijin untuk mengajak isteri Anda nonton film di suatu gedung bioskop pada jam tayang malam hari lagi. Bagaimana respon Anda melihat "kelakuan" ini? Kasus ketiga, soal antarpemeluk agama yang bertikai atas nama agamanya atau kepentingan pemeluknya.

Soal dua orang cidal yang bertengkar, mungkin kisah lucu yaitu saling salah paham dalam berinteraksi. Tetapi secara satiris menggambarkan kepada tugas, hak, dan kewajiban yang berlawanan: membeli versus menjual, tetapi pada titik tertentu, bertemu (bersekongkol) atau konsisten terhadap kewajibannya masing-masing? Soal tilpun seorang lelaki yang meminta ijin mengajak isteri Anda nonton film malam hari hanya berdua (maaf Anda tidak boleh ikut), apakah Anda akan langsung menjawab dengan cara menasehati bahwa "perbuatan yang direncanakan itu dosa?", atau Anda akan memarahi bahkan melakukan tuntutan karena Anda anggap melecehkan 'kehormatan' termasuk kenyamanan suatu rumahtangga orang lain (Anda), atau berpura-pura 'mengijinkan (dalam ucapan) tetapi sebetulnya Anda juga ingin menjebak balik atau memanfaatkan peluang untuk 'saling pinjam' pasangan? Sedang soal keagamaan ada banyak kasus yang pada akhirnya berujung pada kekerasan atau jeratan hukum. Agama yang oleh pemeluknya (masing-masing) diyakini (hanya yang benar), lalu dirinya merasa terpanggil untuk mendakwahkan (kebenaran ajaran agamanya) kepada orang lain, sekaligus merencanakan membangun fasilitasi peribadatan pada saat yang sama berarti atau ditanggapi oleh pemeluk agama lain yang berbeda bahwa sedang terjadi ekspansi bahkan pelecehan, lalu berujung pada konflik.

Berbagai kasus-kasus tadi tentu butuh jawaban dan jalan keluar pemecahan, yang berinti pada apa dan bagaimana mengkonsepkan aturan (hukum) yang dinilai adil. Dari sudut inilah pendekatan interdisiplin dan multidisipline dibutuhkan.

Apa itu realitas dalam kasus-kasus itu? Tidak lebih sebagai "ontologi" dalam bahasa ilmu sosialnya. Bagaimana memahami ontologi tadi? Satu tafsir atau banyak tafsir? Ini soal 
epistemologi. Cara pandang, apakah objektif, subjektif, atau intersubjektif? Lantas, keputusan seperti apa yang "adil" untuk dieksekusi? Ini soal teori dan metodologi yang dijadikan acuan, apakah dengan metode kuantitatif atau metode kualitatif. Tentu 'keputusan akhir" yang dipilih, merupakan persoalan serius dalam kaitannya dengan 'diskusi' semacam "forum shoping" soal adil dan keadilan dalam dunia (ilmu sosial) dan dalam dunia praktik (tindakan). Mengapa?

Karena kata "benar" dalam bahasa ilmu (dalam marka teoritis: das sollen), yakni cara memahami dan mempertimbangkan untuk menemukan "jawaban yang tepat" atas suatu masalah yang 'didefinisikan", tidak selalu sama "tepat" dalam praktik (das sein) kehidupan. Kata "fair play" dalam artian "law in the book" di dunia olah raga (kasus: sepakbola) misalnya, artinya sudah sama-sama diketahui secara relatif persis oleh antarpihak: wasit, pemain, dan penonton. (Pengetahuan bersama dan kesepakatan bersama atas arti fairplay dalam tataran teori, merupakan representasi dari teori fungsional. Tidak ada yang tidak setuju, tetapi keper-setuju-an di sini, berada dalam tataran ideal-culture; das sollen).

Tetapi saat permainan sepakbola itu berjalan, kita (yang kebetulan menonton permainannya) menyaksikan dengan mata-kepala sendiri, bahwa ada banyak kejadian yang menurut definisi fairplay, sudah tidak fair lagi dalam bermain (game). Lawan yang membawa bola menuju ke gawangnya, dijatuhkan. Kalau sang wasit menasihati: "Anda bermain tidak fair, karena itu saya beri hukuman kartu kuning”, kata wasit. Sang pemain yang dianggap tidak bermain "fair" tadi ngloyor sambil senyum. Sewaktu jeda (istirahat), seorang peneliti sosial yang menggunakan pendekatan kualitatif, mendekati sang pemain yang tadi menjatuhkan lawan bertanya, lalu dijawab oleh pemain ybs: "saya tahu, menjatuhkan lawan itu tidak fair, tetapi harus saya lakukan karena pertimbangan rasional sesuai dengan tujuan dari permainan itu sendiri: kalau tidak saya jatuhkan, peluang goal $75 \%$, sedang kalau saya jatuhkan, peluang itu berubah drastis menjadi 25\%). Inilah contoh factual ataau real culture.

Keduanya (pemain dan peneliti) tersenyum "mengerti" (the behavior is meaningful). Di sini "permainan sepakbola di lapangan" merupakan "arena yang menyediakan bahan norma hukum yang hidup, yang senyatanya dianut dalam masyarakat, dan bergerak secara dinamis" Di sini pula teori konflik mulai kelihatan relevansinya untuk digunakan, yaitu dalam realitas sosial selalu ada persaingan untuk memperebutkan peluang-peluang yang menguntungkan, yang direbutkan secara jujur atau tidak jujur.

Semakin kelihatan ketika kita lihat pada kesempatan yang lain (masih dalam dunia sepakbola yang mengagungkan permainan fairplay itu), karena kesebelasan tuan rumah pada menit ke-80, belum bisa memenangkan pertandingan. Maka salah seorang penyerangnya, 
ketika memasuki areal pinalti lawan, melakukan diving dengan cara dan strategi yang sudah terlatih. Secara tersamar atau kasat mata, kelihatan bahwa itu "diving", tetapi sepertinya wasit termasuk para partisipan (suporter kesebelasan tuan rumah) tidak tahu atau pura-pura tidak tahu (kalau dalam bahasa Ervin Goffman: lihatlah 'kalau mau tahu realitas yang sebenarnya' ada pada back stage, bukan front stage. Nah hal ini hanya bisa dijelaskan lewat teori interaksi simbolik). Tendangan pinalti pun dihadiahkan, lalu $0-1$ untuk kesebelasan tuan rumah. Hampir semua partisipan bertepuk tangan kegembiraan (Dalam hal ini kelihatan: tujuan mengalahkan cara, lihat skema lihat skema 'the unit voluntaristic action' Talcott Parsons).

Rupanya, kemenangan 1-0 itu belum memuaskan (berdasarkan kesepakatan konspiratif). Lalu dicarilah moment, bagaimana memberi kepuasan pada tim tuan rumahCaranya, ya hadiah pinalti lagi yang paling mudah. Terjadilah goal yang kedua menjadi 2 - 0 (lihat teori tukar-menukar; exchange theory). Tetapi apa efek 'hukum' yang terjadi? Hampir semua suporter kesebalasan tandang, marah lalu turun ke lapangan, mengejar-ngejar wasit. Wasit ketakutan, lalu lari terbirit-birit minta perlindungan polisi. Tugas polisi adalah meredamkan gejolak (sosial).

Keributan seperti itu, apakah karena masyarakat manusia sedang memperjuangkan 'keadilan substansial', atau sesungguhnya hanya karena soal keahlian di dalam mempermainkan 'ketidakjujuran' itu sendiri. Keributan belum mereda, lalu terjadi perkelahian antarsuporter sampai terjadi korban, sehingga terjadi apa yang disebut dengan 'fenomena hukum' yang membutuhkan keadilan dalam penyelesaian. Mirip dengan diskusi dan mendiskusikan ihwal keadilan oleh para akademisi dan teoritisi.

\section{Masyarakat, Kebudayaan, dan Hukum}

Jika hukum termasuk keadilan itu untuk manusia, dan dikonstruksi juga oleh manusia, sesungguhnya dari mana sumber persoalannya? Jawabannya, pada pertama, kebutuhan dasariah manusia iitu sendiri. Kedua, soal acuan pedoman yang dianggap benar dan baik. Ketiga, soal kemungkinan terjadinya inkonsistensi tindakan dan acuan sehingga berefek kepada persoalan hukum. Dari sudut inilah hukum sebagai norma keadilan menemukan relevansinya.

Untuk itu, secara bertahap bisa kita amati apa sesungguhnya kebutuhan dasariah masyarakat manusia dan bagaimana mereka menentukan pilihan tindakan?

Setiap warga masyarakat memiliki kebutuhan dasariah, yaitu kebutuhan biologis, kebutuhan sosial, dan kebutuhan integratif. Kebutuhan biologis (dalam penjelasan yang 
sederhana) meliputi terpenuhinya: pangan, sandang, dan papan. Pertanyaannya, dengan cara bagaimana memenuhi kebutuhan biologis itu?

Secara umum ialah dengan melibatkan diri dengan orang lain, sehingga memunculkan kebutuhan kedua yaitu kebutuhan sosial. Dorongan untuk terpenuhinya kebutuhan sosial, selain untuk berinteraksi dan membangun kerjasama, juga sekaligus untuk (memenangkan) bersaing dengan kelompok di luarnya ketika ketersediaan sejumlah kebutuhan seperti barang (ekonomi), kekuasaan (politik) terbatas, atau 'kebenaran ideologis' yang selalu dijadikan ajang keributan.

Awal mula perlunya keteraturan sosial dan kontrol sosial. Kepentingan seperti itu (perlu adanya keteraturan sosial dan kontrol sosial) secara tersurat maupun tersirat, menunjukkan adanya kecenderungan umum masyarakat manusia yaitu melakukan penyimpangan untuk berbagai kepentingan yang beragam. Dari sini pula perlunya kebutuhan ketiga yaitu kebutuhan integratif (saya lebih suka menggunakan istilah: kebutuhan adab), seperti kebutuhan untuk merasakan adanya keadilan, yang merupakan puncak dari suatu peradaban masyarakat manusia. Hanya sayangnya, konsepsi adil yang sering dijabarkan ke dalam tindakan yang tepat berdasarkan aturan-aturan dan norma-norma, juga adalah hasil ciptaan manusia yang pembawaan naluriahnya memiliki kecenderungan umum berupa: sentimen kolektif yang sering diskriminatif.

Karena alasan itu pula "adil” senyatanya ada pada konsep "menuju”, bukan konsep "sudah menjadi", sehingga ketika kata "adil" itu disampaikan, spontan muncul jawaban balik: adil menurut siapa?

Dalam pengertian sederhana, "adil" mengacu dan diacukan kepada "menempatkan atau memutuskan suatu perkara secara pas, tepat, dan bijak, dst”. Pertanyaan lanjut ialah: pas, tepat, dan bijak itu bagaimana mengukurnya, mengingat acuan yang dianggap benar lawan salah; baik lawan buruk itu, beragam ukurannya. Belum lagi soal motivasi dan melakukannya. Bagi pekerja hukum, mengandalkan barang bukti. Pertanyaannya: Apakah barang bukti itu sebagai indikasi kebenaran, atau pemahaman dan tafsir atas barang bukti itu sendiri?

Saya mencatat ada lima kategori acuan masyarakat manusia yang dikategorikan sebagai yang benar atau baik (kata lain: kebudayaan dalam arti acuan cara hidup masyarakat manusia), yaitu kebenaran: konstitutif, kognitif, evaluatif, etik, dan ekspresif. Kebenaran konstitutif adalah kebenaran yang didasarkan pada "keyakinan", sebagaimana keyakinan akan kebenaran agama yang dipeluknya. Kebenaran kognitif didasari pada pengalaman dan penalaran sebagaimana diujudkan ke dalam pengetahuan lokal (local knowledge; local 
wisdom) dan pengetahuan ilmiah (scientific knowledge). Kebenaran evaluatif bermuara kepada tradisi seperti adat-istiadat. Kebenaran etik mengacu kepada soal kepatutan sosial sesuai dengan corak dan struktur sosial masyarakat yang ada. Sedang kebenaran ekspresif adalah kesesuaian pada cita rasa indah atau tidak indah seperti dalam dunia seni. Dalam hal ini bersenian juga bisa berkaitan dengan norma hukum. Pada semua jenis-jenis kebenaran itu, memiliki ukuran yang berbeda-beda, baik di dalam ranah yang sama, apalagi yang berbeda.

Kasus antarpemeluk agama bertengkar bahkan melakukan tindakan yang menurut hukum positif sudah dikategorikan 'tindak kriminal', boleh jadi masing-masing pelakunya secara kukuh menyebut diri benar, karena melihat kelompok yang berbeda keyakinan (dan pemahaman keagamaan) pihak lain sebagai salah dan menyesatkan. Karena alasan itu, maka 'atas nama' agama yang mereka pahami, atau sejatinya menurut kepentingan penganut agama itu sendiri (yang belum tentu sesuai dengan ajaran agamanya) bertindak (meski berlawanan dengan hukum positif) diakui sebagai kewajiban. Contoh lain keributan antarpihak soal cara menyikapi hubungan antara ajaran agama dan budaya (lokal).

Ketika terjadi pertikaian yang mengganggu ketertiban umum, bagi pengambil keputusan dengan mengatasnamakan "keadilan" memang tidak mudah, tetapi bagi teoritisi yang tugasnya memahami dan memahamkan realitas yang ada - mestinya justru menjadi tantangan.

Jadi, sejatinya, manusia dan keadilan berada dalam ranah rindu dan benci. Rindu karena kita punya hati nurani, benci karena seringkali bertabrakan dengan naluri dan emosi.

\section{Simpulan}

Ada ungkapan Jawa yang menarik untuk memungkinkan seseorang bisa mendekati perbuatan adil (baca: mulia) dan keadilan, yaitu: paring pepadhang marang wong kang kepetengan; paring teken marang wong kang kelunyon; dan paring unjukan marang wong kang keluwen. Jika diterjemahkan secara bebas pesan di balik ungkapan itu ialah: Pertama, kewajiban moral manusia adalah memberi keterangan secara tepat kepada orang lain yang belum mengerti. Bukan justru memanfaatkan ketidaktahuan pihak lain untuk kepentingan diri atau kelompok. Dengan kata lain, hukum bukan untuk memperoleh keuntungan diri, tetapi untuk keuntungan semua yang terlibat dalam pertikaian dengan cara bijak berkeadilan. Kedua, berilah nasihat kepada mereka yang menunjukkan gejala terjerat hukum. Bukan sebaliknya, memanfaatkan hukum untuk menjeratnya. Ketiga, bahagiakan mereka yang menderita, bukan sebaliknya, 
melakukan tindakan hukum untuk menciptakan penderitaan lawan. Karena itu, atau untuk itu, perlakukan orang lain sebagai kawan, bukan lawan.

\section{Daftar Pustaka}

Asmara, Teddy. 2011. Budaya Ekonomi Hukum Hakim. Semarang: Fasindo.

Geertz, Clifford 1973. The Interpretation of Cultures. New York: Basic Book.

Goffman, Ervin 1963. Behavior in Public Places. New York: The Free Press.

Irianto, Sulistyowati \& Shidarta 2017. Metode Penelitian Hukum. Jakarta: Obor.

Thohir, Mudjahirin 2019. Beragam(a) Itu Indah. Semarang: Orde Buku.

Weber, Max. 2006. Studi Komprehensif Sosiologi Kebudayaan. (The Handbook of Sociology). Yogyakarta: IRCiSod (Terjemahan). 